\title{
Is Percutaneous Fixation Necessary \& Adequate For Dis- placed Supracondylar Fractures of Humerus in Children? - An Institutional Study
}

\author{
Vishal Ashokraj Pushkarna ${ }^{1}$, Vivek Amritbhai Patel $^{2}$
}

1.Assistant Professor Of Orthopaedics, Trauma And Joint Replacement Surgeon, Department Of Orthopaedics, Gujarat Adani Institute Of Medical Sciences, Bhuj, District Kutch, Gujarat, India

2. Associate Professor Of Orthopaedics, Hou \& Senior Joint Replacement Surgeon, Department Of Orthopaedics, Gujarat Adani Institute Of Medical Sciences, Bhuj, District Kutch, Gujarat, India.

Corresponding Author: Dr Vivek Amritbhai Patelassociate Professor Of Orthopaedics, Hou \& Senior Joint Replacement Surgeon, Department Of Orthopaedics, Gujarat Adani Institute Of Medical Sciences, Bhuj, District Kutch, Gujarat, India. vishalpusshkarna@hotmail.com

Submission: 30/11/2020

Review: 30/1/2021

Acceptance: $11 / 2 / 2021$

DOI:10.47799/pimr.0902.14

\section{ABSTRACT}

Supracondylar humerus fracture (SCHF) is frequently encountered in pediatric age group and nearly three fourth of all upper extremity fractures. Most commonly used technique for surgical treatment in the displaced SCHF in children is closed reduction and stabilization with percutaneous pins.

Aim: This retrospective study was conducted to find out the outcome and safety of percutaneous pinning techniques which includes lateral pinning and cross pinning in terms of functional and radiological outcome in the management of displaced supracondylar humerus fractures in children and to see the associated complications with this method of fixation.

Materials \& Methods: This retrospective study comprising of 40 cases of displaced supracondylar humerus fracture, treated with lateral or cross pinning was carried out at Orthopedics Department, Gujarat Adani Institute of Medical Sciences and G.K General Hospital, Bhuj from July 2019 to june2020. The inclusion criteria were: a) Gartland extension type II, III, b) age below 12 years, c) presented to OPD/Emergency within 48 hours of injury, d) closed and gustilo grade I open fractures, Patients with: a) extension Type I of fractures, b) flexion type injuries, c) except Gustilo grade 1 open fracture d) age more than 12 year e) pervious history of fractures or nerve injury around the elbow, were excluded from the study.

Results: Out of the 40 patients, 25 (62.5\%) were male and $15(37.5 \%)$ were female. The children were aged 2 years to 12 years with a median age of 7.67 years. There were 19 left sided and 21 right-sided fractures. 29 children had an injury while playing and 11 had a fall from a height. functional results in our study were $67.5 \%$ of cases had excellent results, $25 \%$ had good results, $5 \%$ had a fair result and $2.5 \%$ had a poor result. $75 \%$ of cases had excellent cosmetic results were $17.5 \%$ of cases had good results, $5 \%$ had fair result and only one case had a poor result.

Conclusion: In our study, we found that anatomical reduction and intra- operative stability will dictate the type of configuration to be used in SCHF.

Keywords: SupracondylerHumerusFracture(SCHF), Children, kwire, Lateral pin, Crossed pin.

\section{INTRODUCTION}

Supracondylar humerus fractures are one of the commonest fractures in children. They cause significant disability in the children as a temporary \& if left untreated as a permanent manner. The most unwanted complications of forearm the Volkmann's ischemic consequences are also related with these fractures.

Supracondylar fracture of humerus (SFH) is frequently encountered in the immature skeleton, predominantly in the non-dominant extremity ${ }^{1}$.Mostly; these fractures are due to a fall from height (e.g., swings) but to less extent can occur after a fall on the ground level ${ }^{2}$. According to the direction of distal fragment, in children's supracondylar humerus fractures is divided into extension type $97.8 \%$ and flexion type 
$2.2 \%{ }^{3}$.Gartland's classification is used to describe this fracture and it is based on displacement in coronal plane radiographs. Type I: un-displaced fractures or minimally displaced fracture with intact anterior humeral line. Type II hinged fractures with the posterior cortex intact, and Type III completely displaced fractures, breach in the posterior cortex ${ }^{4}$. Later, Leitch et al., Added type IV, describing multidirectional instability ${ }^{5}$.

Surgical technique used for treatment in the displaced SCHF (type II, III, IV) in children is closed reduction and stabilization with percutaneous pins ${ }^{6}$.Different configuration of pinning is used depending upon fracture pattern which includes lateral only pins which may be two or three in numbers or two cross pinning configurations. Biomechanically, a crossed pin configuration (one medial and one lateral) provides increased stability, but carries the risk of iatrogenic ulnar nerve injury during insertion of the medialpin ${ }^{7,8}$. Conversely, lateral pin fixation avoids the danger of iatrogenic ulnar nerve injury, but has been proven to be mechanically less stable compared to crossed pin configuration ${ }^{8,9}$. Studies are there which shows lateral pins specially divergent configuration are good enough for maintaining reduction. Still there is controversy regarding choice of pinning configuration and based primarily on the surgeons' preference.

This study was conducted to find out the functional outcome of closed reduction and percutaneous pinning techniques in the management of displaced supracondylar humerus fractures in children.

\section{MATERIALS \& METHODS:}

This Retrospective study comprising of 40 cases of displaced supracondylar humerus fracture, treated with lateral or cross pinning was carried out atTertiary care Orthopedics Department, Gujarat Adani Institute of Medical Sciences and G.K General Hospital, Bhuj from July 2019 to June 2020.All the patients operated by senior Orthopedic Surgeon after taken necessary consents from the patients \& relatives.

The inclusion criteria were: a) Gartland extension type II, III, b) age below 12 years, c) presented to OPD/Emergency within 48 hours of injury, d) closed and Gustilo grade I open fractures.

Exclusion criteria were a) extension Type I of fractures, b) flexion type injuries, c) except Gustilo grade 1 open fracture d) age more than12-year e) pervious history of fractures or nerve injury around the elbow, were excluded from the study.

Proper clinical and radiological examination and preoperative workup was done.Gartland's classification was used to classify fracture type. In the operation theater closed reduction was done, under general anesthesia and reduction was confirmed under image intensifier, transcutaneous pin fixation was then done under direct visualization of image intensifier. Size of K-wires used for fixation was 1.8- or 2. 0$\mathrm{mm}$. Patients in which cross pinning technique was used in such cases medial pin was inserted with small incision over medial epicondyle and in order to prevent ulnar nerve injury, elbow was kept in less flexion around 45 to 60 degreesand wire was placed over the epicondyle, anterior to ulnar groove.Vascularity of distal limb were also checked at this point. The pins were bent and cut off outside the skin and a wellpadded, above-elbow, back-slab was applied and vascularity of the distal part of limb checked again.

\section{Post-operative care and Rehabilitation}

Patient was observed for 24 hours with limb elevation and was discharged in above elbow pop slab. Follow up was done on 6th day and 14th day to inspect any pin tract infection and swelling, then on 4th and 6th week to assess radiological union and any pin loosening. $K$ wire and pop slab was removed at 6 th week and proper physiotherapy were started. 8th week follow up was done to check progress. Final follow up was on the 4th month post op. The results were analyzed using the Flynn criteria8.These criteria are divided into two components, the functional and the cosmetic component and both are further sub-divided as excellent, good, fair and poor at an interval of five degrees.

\section{Results:}

Out of the 40 patients, 25 (62.5\%) were male and 15(37.5\%) were female. (Graph I). The children were aged 2 years to 12 years with a median age of 7.67years. (Table 1 ). There were 19 left sided and 21 right-sided fractures. (Graph II). 29 children had an injury while playing and 11 had a fall from a height. Out of 40 patients one patient having Gustilo type one fracture. The extension type II was14 and 26 were of extension type III. (Graph III). Out of all cases, 4 cases were treated by two lateral $k$-wires while 33 were treated by 3 lateral k-wires while only 3 cases were treated with cross pinning. (Table 2). Threeof the fractures required open reduction. There were no cases of vascular or nerve injuries, pre-operatively. During follow-up, one case had a secondary displacement of wires and loss of reduction. Post-operatively, no patient had a pin track infection or pin migration. Postoperatively, in one case median nerve injury was noted which recovered in 5 weeks. Callus formation was seen in all patients at the 4 th week postoperative follow up before removing the K-wires. No case of nonunion was seen. Results were analyzed using Flynn's criteria ${ }^{8}$.

According Flynn's criteria; satisfactory functional results in our study were $67.5 \%$ of cases had excellent results, $25 \%$ had good results, $5 \%$ had a fair result and $2.5 \%$ had a poor result. $75 \%$ of cases had excellent cosmetic results were $17.5 \%$ of cases had good results, $5 \%$ had fair result and only one case had a poor result. (Tables 4,5,6,7,8). 
TABLE 1: DISTRIBUTION OF PATIENTS AS PER AGE

\begin{tabular}{|c|c|c|c|c|}
\hline Age & $0-5$ years & $6-10$ years & More than 10 years but less than 12 years & Total \\
\hline Male & 4 & 15 & 6 & 25 \\
\hline Female & 2 & 10 & 3 & 15 \\
\hline
\end{tabular}

Table 2: According to method of fixation

\begin{tabular}{|c|c|c|}
\hline Approach & Numbers & Percentage \\
\hline Lateral 2 pin & 4 & $10 \%$ \\
\hline Lateral 3 pin & 33 & $82.5 \%$ \\
\hline Cross Pinning (medial and lateral pinning) & 3 & $7.5 \%$ \\
\hline
\end{tabular}

Table 3: According to Fracture Type Pinning Method

\begin{tabular}{|c|c|c|c|c|}
\hline Type Of fracture & 2 Lateral pins & 3 Lateral Pins & Cross Pinning & 0 \\
\hline Type II & 4 & 10 & 3 & 26 \\
\hline Type III & 0 & 23 & 3 & \\
\hline Total & 4 & 33 & & \\
\hline
\end{tabular}

Table 4: Flynn Criteria for Grading Results

\begin{tabular}{|l|l|l|l|}
\hline \multirow{2}{*}{ Results } & \multicolumn{1}{|c|}{ Rating } & $\begin{array}{c}\text { Cosmetic Factor: Loss of Carrying } \\
\text { Angle (Degrees) }\end{array}$ & $\begin{array}{l}\text { Functional Factor: Loss of } \\
\text { Motion (Degrees) }\end{array}$ \\
\hline \multirow{3}{*}{ Satisfactory } & Excellent & $0-5$ & $0-5$ \\
\cline { 2 - 4 } & Good & $6-10$ & $6-10$ \\
\cline { 2 - 5 } & Fair & $11-15$ & $11-15$ \\
\hline Unsatisfactory & Poor & $>15$ & $>15$ \\
\hline
\end{tabular}

Table 5: Functional Result: Range of motion (ROM)

\begin{tabular}{|c|c|c|c|c|}
\hline Results & Rating & $\begin{array}{l}\text { Functional Factor: Loss of Motion } \\
\text { (Degrees) }\end{array}$ & $\begin{array}{l}\text { Outcome of } \\
\text { patients }\end{array}$ & $\begin{array}{l}\text { Percentage } \\
\qquad(n=26)\end{array}$ \\
\hline \multirow{3}{*}{ Satisfactory } & Excellent & $0-5$ & 27 & $67.5 \%$ \\
\hline & Good & $6-10$ & 10 & $25 \%$ \\
\hline & Fair & $11-15$ & 2 & $5 \%$ \\
\hline Unsatisfactory & Poor & $>15$ & 1 & $2.5 \%$ \\
\hline
\end{tabular}

Table 6: Functional Result According to Pin Configuration: Range of motion (ROM)

\begin{tabular}{|c|c|c|c|}
\hline & Lateral 2 pin & Lateral 3 pin & Cross Pinning \\
\hline Excellent & 2 & 23 & 1 \\
\hline Good & 2 & 7 & 0 \\
\hline Fair & 0 & 3 & 2 \\
\hline
\end{tabular}


Vishal et al

ISSN (P) 2348-1447

ISSN (0) 2338-229X

www. pimr.org.in

Table 7: Cosmetic Results

\begin{tabular}{|l|l|l|l|l|}
\hline \multirow{2}{*}{ Results } & \multicolumn{1}{|c|}{ Rating } & $\begin{array}{c}\text { Cosmetic Factor: Loss of Carrying } \\
\text { Angle (Degrees) }\end{array}$ & \multicolumn{1}{|c|}{$\begin{array}{c}\text { Outcome in } \\
\text { patients }\end{array}$} & \multicolumn{1}{c|}{$\begin{array}{c}\text { Percentage } \\
(\mathrm{n}=26)\end{array}$} \\
\hline \multirow{3}{*}{ Satisfactory } & Excellent & $0-5$ & 30 & $75 \%$ \\
\cline { 2 - 6 } & Good & $6-10$ & 7 & 2 \\
\cline { 2 - 6 } & Fair & $11-15$ & 1 & $5 \%$ \\
\hline Unsatisfactory & Poor & $>15$ & $2.5 \%$ \\
\hline
\end{tabular}

Table 8: Cosmetic Result According to Pin Configuration

\begin{tabular}{|c|c|c|c|}
\hline & Lateral 2 pin & Lateral 3 pin & Cross Pinning \\
\hline Excellent & 3 & 24 & 2 \\
\hline Good & 1 & 7 & 0 \\
\hline Fair & 0 & 2 & 0 \\
\hline
\end{tabular}

Figure 1: Pre-operative X-ray
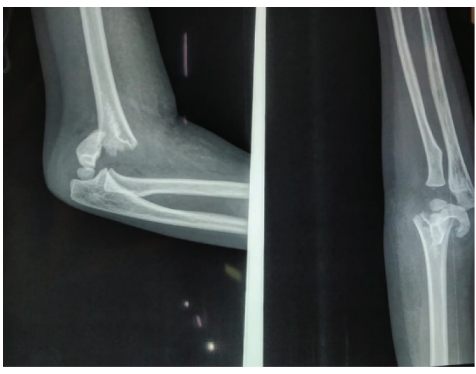

Figure 2: Immediate Post-operative x-ray

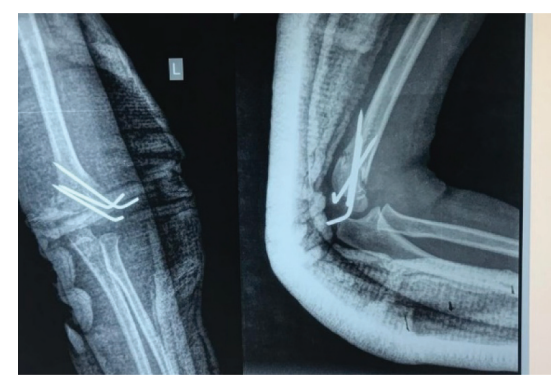

Figure 3: 3 months Post-operative X-ray

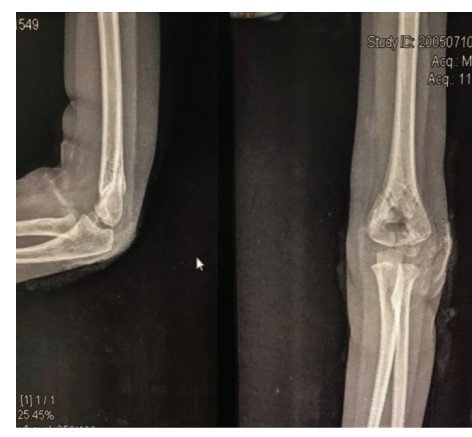

Figure 4: Clinical Picture

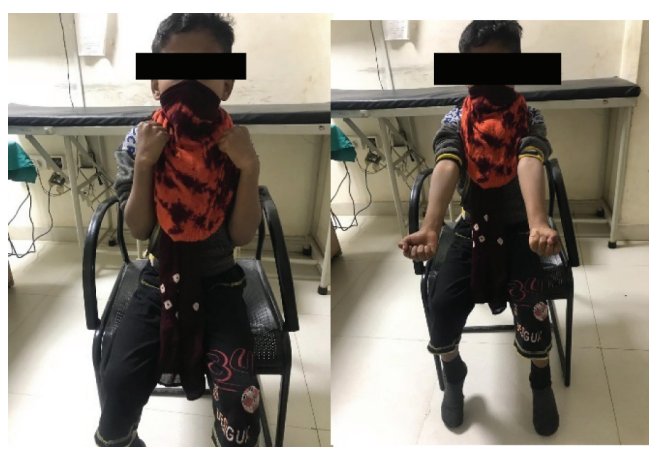

Discussion:

Fractures of the supracondylar region of the distal humerus are common in children and constitute $86.4 \%$ of all fractures of the ulna in the elbow region. All humerus fracture type-III by Gartland in children should be surgically treated \& not the conservatively. ${ }^{22}$

Success of SCHF depends on good reduction and proper stability achieved with $\mathrm{k}$-wire, so that reduction is maintenance until fracture unites. Controversy persists regarding the optimal pin fixation technique. It involves the use of two or three lateral pins which are placed in either a parallel or a divergent pattern and cross pinning where one pin is inserted from the medial side20. There is a significant risk of iatrogenic ulnar nerve injury during medial pinning in crossed configuration with an incidence rate of $0-6 \%{ }^{21}$. Whereas, in lateral pinning technique, there is a chance of loss of reduction due to biomechanically less stable, and most common complication of poor or loss of reduction during treatment is cubitus varus with an incidence of $3-57 \%{ }^{21}$. Chakraborty et al. and Balakumar and Madhuri 
found crossed (medial/lateral) pinning to be superior than two parallel lateral pin Fixations ${ }^{15-16}$. However, many studies have reinforced the observation that both lateral-entry pin fixation and crossed pin configuration are effective in the management of Type III Gartland supracondylar fractures in children.

Govindasamy et al. did a retrospective study on Cross pinning versus lateral pinning in supracondylar fracture in children and concluded that both fixation techniques were good in terms of stability, function and cosmetic outcome18. The problem with cross pinning was iatrogenic ulnar nerve injury due to medial pinning which was $11 \%$. So lateral pinning is a reliably safe method and provides adequate stability in displaced supracondylar fractures.

In the current concept of Bloom et al, they reported that three lateral pins were biomechanically equivalent to two cross pins; but that the cross pins provided more stable fixation than the two lateral pins ${ }^{19}$.

In our study out of 40 cases, two lateral pins were used in 4 cases, 33 cases 3 lateral pins were used, and 3 cases cross pinning was done. The mode of injury was mostly fall while playing. In one case median nerve injury were reported which was recovered and in one case loose of reduction was there. The choice of the pin configuration was based on the intraoperative stability using continues fluoroscopic examination after pin fixation and the severity of the elbow swelling.

Few limitations of this study were sample size, which is less and secondly, short term follow-up.

\section{Conclusion:}

Our study found that stability according to fracture configuration plays important role while choosing the fixation methods for the supracondylar humerus fractures in children(SCHF).For type 3 fractures the 3 lateral pin can be adequate while in type 2 fractures two or three lateral pins can be a good treatment. We found that if there is a comminution of the medial wall or unstable SCHF cross pinning will give you better results thanonly lateral pinning. The percutaneous fixation provides good initial stability to the factures in these extremely morphogenic unstable fractures leads to early mobilization. These fixations also provide easy removal of hardware with less chances of physical damage. Still in our study there was no significant difference in patient outcomes in between cross pins and lateral pin entry in terms of functional and radiological outcome, union and other surgical complication \& may be very long randomized controlled trial can fetch these data. But the results of the method in our study looks very attractive $\&$ can significantly reduce future morbidity for the future working hands of the nation.

\section{REFERENCES}

1. Davis, Richard T. MD; Gorczyca, John T. MD; Pugh, Kevin MD Supracondylar Humerus Fractures in Children, Clinical Orthopaedics and Related Research: July 2000 - Volume 376 - Issue - p 49-55

2. Shannon FJ, Langhi S, Mohan P, Chacko J, D'Souza L. PERCUTANEOUS LATERAL CROSS WIRING FOR SUPRACONDYLAR FRACTURES OF THE HUMERUS IN CHILDREN. InOrthopaedic Proceedings 2003 Feb (Vol. 85, No. SUPP_II, pp. 138-138). The British Editorial Society of Bone \& Joint Surgery.

3. Otsuka NY, Kasser JR. Supracondylar fractures of the humerus in children. JAAOS-Journal of the American Academy of Orthopaedic Surgeons. 1997 Jan 1;5(1):1926.

4. Schoenecker JG, Bae DS. Fractures of the distal radius and ulna. Flynn JM, Skaggs DL, Waters PM. Rockwood and Wilkins, Fractures in Children. 8th edition. Philadelphia, USA: Wolters Kluwer. 2015:349-412.

5. Gartland J. Management of supracondylar fractures in children. Surg Gynecol Obstet. 1959;109:145-54.

6. Leitch KK, Kay RM, Femino JD, Tolo VT, Storer SK, Skaggs DL. Treatment of multidirectionally unstable supracondylar humeral fractures in children: a modified Gartland type-IV fracture. JBJS. 2006 May 1;88(5):980-5.

7. Casiano E. Reduction and fixation by pinning "Banderillero" style-fractures of the humerus at the elbow in children. Military medicine. $1960 \mathrm{Apr}$ $1 ; 125(4): 262-4$.

8. Flynn JC, Matthews JG, Benoit RL. Blind Pinning of Displaced Supracondylar Fractures of the Humerus in Children: SIXTEEN YEARS'EXPERIENCE WITH LONG-TERM FOLLOW-UP. JBJS. 1974;56(2):263-72.

9. Larson L, Firoozbakhsh K, Passarelli R, Bosch P. Biomechanical analysis of pinning techniques for pediatric supracondylar humerus fractures. Journal of Pediatric Orthopaedics. 2006 Sep 1;26(5):573-8.

10. Eberhardt O, Fernandez F, Ilchmann T, Parsch K. Cross pinning of supracondylar fractures from a lateral approach. Stabilization achieved with safety. Journal of children's orthopaedics. 2007 Jul 1;1(2):127-33.

11. Gordon JE, Patton CM, Luhmann SJ, Bassett GS, Schoenecker PL. Fracture stability after pinning of displaced supracondylar distal humerus fractures in children. Journal of Pediatric Orthopaedics. 2001 May 1;21(3):313-8.

12. Lee SS, Mahar AT, Miesen D, Newton PO. Displaced pediatric supracondylar humerus fractures: 
biomechanical analysis of percutaneous pinning techniques. Journal of Pediatric Orthopaedics. 2002 Jul 1;22(4):440-3.

13. Zionts LE, McKellop HA, Hathaway R. Torsional strength of pin configurations used to fix supracondylar fractures of the humerus in children. The Journal of bone and joint surgery. American volume. 1994 Feb 1;76(2):253-6.

14. Kallio PE, Foster BK, Paterson DC. Difficult supracondylar elbow fractures in children: analysis of percutaneous pinning technique. Journal of pediatric orthopedics. 1992 Jan 1;12(1):11-5.

15. Begovic N, Paunovic Z, Djuraskovic Z, Lazovic L, Mijovic T, Babic $S$. Lateral pinning versus others procedures in the treatment of supracondylar humerus fractures in children. Acta Orthop Belg. 2016 Dec 1;82(4):866-71.

16. Balasubramanian Balakumar VM. A retrospective analysis of loss of reduction in operated supracondylar humerus fractures. Indian journal of orthopaedics. 2012 Nov;46(6):690.

17. Govindasamy R, Gnanasundaram R, Kasirajan S, Thonikadavath F, Tiwari RK. Cross pinning versus lateral pinning in type III supracondylar fracture: A retrospective analysis. Int J Res Orthop. $2016 \mathrm{Jul} ; 2(3): 138-42$.

18. Bloom T, Robertson C, Mahar AT, Newton P. Biomechanical analysis of supracondylar humerus fracture pinning for slightly malreduced fractures. Journal of Pediatric Orthopaedics. 2008 Oct 1;28(7):766-72.

19. Madjar-Simic I, Talic-Tanovic A, Hadziahmetovic Z, SaracHadzihalilovic A. Radiographic assessment in the treatment of supracondylar humerus fractures in children. Acta Informatica Medica. 2012 Sep;20(3):154.

20. Green DW, Widmann RF, Frank JS, Gardner MJ. Low incidence of ulnar nerve injury with crossed pin placement for pediatric supracondylar humerus fractures using a mini-open technique. Journal of orthopaedic trauma. 2005 Mar 1;19(3):158-63.

21. Buturovic S, Krupic F. Comparison of treatment results for fractures of the distal humerus in children according to the indication for conservative or surgical solution. Materia socio-medica. 2014 Aug;26(4):242.

How to cite this article: Pushkarna V, Patel V. Is Percutaneous Fixation Necessary \& Adequate For Displaced Supracondylar Fractures of Humerus in Children? - An Institutional Study.Perspectives in Medical Research 2021; 9 (2):63-68

DOI:10.47799/pimr.0902.14

Sources of Support: Nil, Conflict of interest: None declared 